\title{
COMPORTAMENTO ECOLÓGICO: UM ESTUDO COM OS ESTUDANTES DE ADMINISTRAÇÃO E CIÊNCIAS CONTÁBEIS DA UNIVERSIDADE FEDERAL DE SANTA MARIA- RS.
}

\author{
ECOLOGICAL BEHAVIOR: A STUDY WITH BUSINESS \\ ADMINISTRATION STUDENTS AND FINANCIAL SCIENCES \\ OF THE FEDERAL UNIVERSITY IN SANTA MARIA- RS
}

\author{
Ana Paula Perlin ${ }^{1}$ \\ Clandia Maffini Gomes ${ }^{1}$ \\ Bárbara Parnov Machado ${ }^{1}$ \\ Francies Motke ${ }^{1}$ \\ Gabriela Rossato ${ }^{1}$
}

Recebido em: 16/02/2016 Aceito em: 16/08/2016

anapaula.perlin@yahoo.com.br
Resumo: O objetivo deste estudo é analisar a o comportamento ecológico dos estudantes de Administração e de Ciências Contábeis da Universidade Federal de Santa Maria. Adotou-se como metodologia a pesquisa descritiva e a abordagem quantitativa. Por meio de uma survey com os estudantes foi aplicado o instrumento composto da Escala de Comportamento Ecológico (ECE), de Pato e Tamayo (2006). A partir dos resultados foi possível constatar que estudantes participantes da pesquisa têm um comportamento ecológico esperado principalmente em questões como o resguardo em jogar papel no chão. Entretanto, algumas questões como o desperdício de água parecem ser bastante comuns entre esses jovens, não tendo completo entendimento do quão importante é o consumo consciente nas atividades diárias deste recurso.

Palavras-chave: Comportamento Ecológico. Sustentabilidade. Estudantes.

Abstract: The objective of this study is to analyze the ecological behavior of students Administration and Accounting from the Federal University of Santa Maria. It was adopted as methodology the descriptive and quantitative approach. Through a survey with students was applied the compound instrument of Ecological Behavior Scale (EBS), duck and Tamayo (2006). From the results it was found that survey participants Students have an expected environmental performance mainly on issues such as fenced in playing paper on the floor. However, some issues such as water waste seems to be quite common among these young people not having full understanding of how important it is conscious consumption in the daily activities of this resource.

Keywords: Ecological behavior. Sustainability. Students.

\footnotetext{
${ }^{1}$ Universidade Federal de Santa Maria - UFSM - Santa Maria - Rio Grande do Sul - Brasil.
} 


\section{INTRODUÇÃO}

A discussão a respeito da importância da sustentabilidade como garantia da manutenção das gerações futuras e como um fator de vantagem competitiva vem instigando uma consciência em prol do meio ambiente. O consumo sustentável dos indivíduos, a gestão sustentável por parte das organizações e todas as práticas ligadas à preservação do meio ambiente e da sociedade são exemplos de atividades que podem despertar comportamentos e valores dos indivíduos.

De acordo com os ambientalistas, os problemas relacionados ao meio ambiente estão ligados ao comportamento humano e qualquer esforço ou posicionamento pró-ambiental, necessita de mudanças no comportamento humano individual (ZELEZNY e SCHULTZ, 2000).

O comportamento direcionado ao consumo sustentável ou ecológico pode ser conceituado como agir em favor do meio ambiente, podendo ser essa ação consciente e intencional ou não, aprendida e desenvolvida por meio da aprendizagem, internacionalizada e presente no dia-a-dia dos indivíduos (PATO; TAMAYO, 2006; PATO, 2004).

Conforme Dias (2006) et al., ao mesmo tempo em que a necessidade de rever conceitos e posturas frente ao meio ambiente é defendida pelos ambientalistas, mídia e educadores, vários questionamentos são colocados com relação à efetiva mudança de comportamento dos indivíduos, especialmente dos jovens. Para alguns, a juventude atual estaria cada vez mais distante do comportamento ecologicamente correto, no entanto para outros essa juventude seria o grande agente das mudanças tão necessárias.

Desse modo, o objetivo deste trabalho é analisar o comportamento ecológico dos estudantes dos cursos de Administração e de Ciência Contábeis da Universidade Federal de Santa Maria. Por se tratarem de jovens que estão presentes em instituições que têm papel fundamental na formação de futuros agentes de transformação e cidadãos mais conscientes da importância da sua relação com o meio ambiente, espera-se que o comportamento ecológico destes indivíduos possa talvez nos indicar que futuros administradores e contadores possam agir de acordo com os limites estabelecidos entre 0 homem e a natureza.

\section{REFERENCIAL TEÓRICO}

O referencial teórico do presente estudo aborda questões acerca da sustentabilidade e da sua relação com a educação, além disso, o estudo apresenta como foco principal o comportamento ecológico, apresentando sua contextualização e aplicações.

\subsection{Perspectivas da Sustentabilidade}

O conceito de sustentabilidade começa a ser desenvolvido, em vista da preocupação com o meio ambiente, já que esse é um assunto em crescente discussão no âmbito global. Nesse contexto, Brito e Lombardi (2007) discorrem acerca da importância do debate a respeito do ambiente 
sustentável, na qual sustenta-se no processo de mudança, visto que a exploração dos recursos, a direção dos investimentos e a orientação do desenvolvimento tecnológico das organizações e da sociedade tratem os recursos naturais sendo finitos, já que a má utilização pode acarretar em danos globais e esgotamento das suas fontes.

A ineficiente utilização dos recursos naturais era algo percebido e debatido em movimentos ambientalistas, desde a década de 70. Como exemplo a Conferência das Nações Unidas para o Meio Ambiente em Estocolmo, ocorrida em 1972, em que ocorreu uma divergência de opinião a respeito do assunto entre países desenvolvidos, que tinham como posição a defesa do controle e redução da poluição, e países subdesenvolvidos, que acreditavam que esse controle desaceleraria o seu crescimento. Dessa maneira, salienta-se o conceito de sustentabilidade, para Freitas (2012) assim se define sustentabilidade:

\footnotetext{
Trata-se de um princípio constitucional que determina, com eficácia direta e imediata, a responsabilidade do Estado e da sociedade pela concretização solidária do desenvolvimento material e imaterial, socialmente incluso, durável e equânime, ambientalmente limpo, inovador, ético e eficiente, no intuito de assegurar preferencialmente de modo preventivo e precavido, no presente e no futuro, o direito ao bem estar.
}

A sustentabilidade deve ser analisada por meio de três pilares, sendo eles os aspectos econômicos, sociais e ambientais, conhecidos também como tripé da sustentabilidade. Além disso, Elkington (2001) se refere ao pilar da economia como o lucro da empresa, ou seja, relaciona a sustentabilidade econômica não comprometendo o desenvolvimento econômico da organização, enquanto ao pilar social, refere-se ao capital humano e o incentivo da equidade entre seus stakeholders, para que assim diminua as diferenças sociais, e por fim trata do pilar ambiental definindo-o como sendo a preservação do capital natural, visando a preservação às gerações futuras. Sendo assim, para uma organização obter reconhecimento sustentável é necessário pôr em prática o tripé da sustentabilidade.

Almeida (2002) ressalta sobre a mudança de paradigma, do desenvolvimento clássico consumidor de recursos naturais, no qual o homem é percebido como um animal de produção, para um nível maior, de formulação do conceito de desenvolvimento sustentável. Esse novo paradigma está em andamento e refere-se a gestão do desenvolvimento, pontual ou abrangente, seja ela nos governos ou nas empresas, fundamentadas nas dimensões ambiental, econômica e social, tendo como foco assegurar a preservação ambiental, da infraestrutura econômica e da sociedade. O velho pensamento cartesiano parece não ser mais eficaz, as atividades sejam elas de qualquer natureza não podem ser pensadas ou praticadas de maneira separada, sendo substituída por uma visão mais holística, participativa, onde a integração e a inter-relação fazem parte dos processos, e tudo parece estar em permanente diálogo (ALMEIDA, 2002).

Parece ser evidente que as práticas sustentáveis são essenciais para as organizações no contexto atual, inclusive as de cunho educacionais, como citado por Jacobi (2003), que sustenta a necessidade de abordar o tema da complexidade ambiental na educação para a sustentabilidade. Diante disso o conceito de educação ambiental (EA) tem grande importância. Silva et al. (2013) corrobora afirmando que a educação é um elemento fundamental na busca pela sustentabilidade, já 
que incentiva a busca por indagações e respostas mais adequadas, pela compreensão e disseminação de novas práticas, pela conscientização e mudança de comportamento e pelo incentivo a respeito à vida, dentre outros tantos aspectos. Dessa maneira a educação traz como herança a mudança de pensamento, a tomada de consciência e também influência no comportamento das pessoas, inclusive a educação ambiental que desenvolve o comportamento ecológico nos indivíduos.

Os estudos referentes a essa temática parecem apresentar um significativo crescimento nos últimos anos. De acordo com Rocha et al. (2013) no período de 1991 a 2012, foram encontradas 2.419 publicações em duas bases internacionais com os termos "educação" e "susrentabilidade", comparando ambas as bases pesquisadas, os autores verificaram que o número de publicações aumentou de forma expressiva na última década e que os Estados Unidos lidera o ranking quanto ao número de publicações, e dentre as publicações mais citadas estão as relacionadas a area da saúde.

\subsection{Comportamento Ecológico}

As questões relacionadas a preservação do meio ambiente e das gerações futuras estão cada vez mais presentes no cotidiano dos indivíduos e das organizações. Ricklefs (2003) afirma que as ações ecológicas são discutidas como fundamentais no âmbito de diminuir os impactos ambientais e estimular o desenvolvimento sustentável. Estas ações são percebidas como essenciais para a resolução dos problemas ambientais, estando relacionadas com a aplicação dos princípios da ecologia no contexto político, econômico e social.

Desse modo entende-se que os indivíduos podem ser os grandes agentes de mudança no meio social. O consumidor pode adotar práticas em favor do meio ambiente e da natureza, por meio da minimização de suas atividades cotidianas sobre o meio ambiente, adotando comportamentos próambientais, como por exemplo, o não desperdício dos recursos naturais, consumo racional e preocupação em termos de sustentabilidade (CAMPOS e POL, 2010).

Devido à variedade de enfoques dados ao assunto, encontra-se na literatura uma diversidade de denominações, que se referem ao comportamento em favor do meio ambiente. Pato e Tamayo (2006) apontam que o conceito de agir em favor do meio ambiente além de ser chamado de comportamento ecológico pode ser referenciado como comportamento verde, pró-ecológico, ambiental, pró-ambiental ou ambientalmente correto.

A denominação comportamento ecológico foi adotada primeiramente por Axelrod e Lehman (1993), Kaiser e Fuhler (2003), os quais definiram o comportamento ecológico como ações que contribuem para preservação ambiental ou para a conservação do meio ambiente. Essa ação em prol do meio ambiente, de acordo com Pato e Tamayo (2006) podem ser conscientes e intencional ou não, podendo também ser aprendida e internalizada, fazendo parte do cotidiano das pessoas.

Nas suas investigações Pato (2004), adota uma definição de comportamento ecológico que considera as intenções e a consciência das práticas favoráveis ambientalmente e os impactos das mesmas. Segundo a autora esse comportamento indica uma preocupação com o meio ambiente e repercute no uso sustentável dos recursos. Esse comportamento expõe dois aspectos fundamentais: "uma ética que se baseia principalmente em princípios de sustentabilidade e qualidade de vida; e 
motivações que pressupõem atitudes não agressivas ou prejudiciais ao meio ambiente" (PATO, 2004, p.9).

Karp (1996) em seu estudo afirma que há três tipos de comportamento ecológico. O primeiro tipo é o do bom cidadão, que procura não sujar os ambientes, recicla latas e papéis, evita o desperdício de água e energia. O segundo tipo é o do ativista, que colabora economicamente com seu esforço para o apoio a grupos ambientalistas. Por fim, destaca-se o do consumidor saudável, que evita comprar produtos poluidores do meio ambiente, não consome alimentos com conservante, e sim produtos orgânicos, relacionando comportamento pró-ambiental com as prioridades de valores.

No que se refere a mensuração das atitudes frente ao meio ambiente, foram desenvolvidas algumas escalas no ambiente internacional, destacando-se a Escala do Novo Paradigma Ecológico (NEP) de Dunlap e Van Liere (1978) que mede a relação dos indivíduos com o meio ambiente de forma mais ampla.

Ao perceber a inconsistência das escalas de comportamentos e crenças ambientais para a realidade socioambiental brasileira, Pato (2004), desenvolveu e validou três instrumentos. A Escala de Comportamento Ecológico (ECE), que deu origem posteriormente a Escala de Percepção de Comportamento Ecológico (EPCE), e ainda a Escala de Crenças Ambientais (ECA).

A Escala de Comportamento Ecológico proposta por Pato e Tamayo (2006) é composta de 34 itens que mensuram os comportamentos ecológicos. Essa escala envolve itens correspondentes aos comportamentos antiecológicos e cinco itens que medem a desejabilidade social, determinada em outras pesquisas como o fator influenciador do comportamento dos indivíduos.

Conforme Beuron (2012), ao buscar uma medida dos comportamentos ecológicos individuais, amplia-se a compreensão das relações entre esses comportamentos e o meio ambiente. Na tentativa de procurar desvendar os elementos necessários à origem de tal comportamento, os valores podem ser utilizados como forma de entender as aspirações individuais que podem explicar tais condutas ambientais.

\section{MÉTODO DO ESTUDO}

Com o objetivo de verificar a influência dos valores pessoais em relação ao comportamento ecológico dos estudantes de ensino médio de Santa Maria, a abordagem do estudo se caracteriza como quantitativa, do tipo descritivo. O principal objetivo da pesquisa descritiva consiste na descrição de algo, ou na exposição de um fenômeno, verificando o grau de associação entre as variáveis trabalhadas (MALHOTA, 2006). Ainda de acordo com Trivinos (1987), o estudo descritivo pretende descrever as características de determinado fenômeno ou estabelecer relações entre algumas variáveis.

Desse modo, o método utilizado para a coleta de dados será o survey. Conforme Malhota (2006), esse método consiste na entrevista estruturada direta, método utilizado quando a pesquisa envolve entrevista com um grande número de pessoas, sendo aplicada a elas uma série de perguntas.

Estudos do CEPE [ISSN 1982-6729]. Santa Cruz do Sul, n. 44, p. 84-99, jul./dez. 2016. 
A população deste estudo são os acadêmicos dos cursos de Administração e Ciências Contábeis, diurno e noturno, da Universidade Federal de Santa Maria - UFSM. A amostra é caracterizada como não-probabilística por acessibilidade e a coleta de dados foi realizada no mês de junho de 2015.

Em relação as variáveis a serem estudadas utilizou-se a escala de comportamento ecológico - ECE, desenvolvida por Franco (2012), baseada em Pato (2004) e Campos (2008). O tratamento dos dados foi realizado por meio do software Statistical Package for the Social Sciences - SPSS 22 , sendo realizadas análises estatísticas descritivas e inferenciais, através dos testes ANOVA e Teste T.

\section{RESULTADOS E DISCUSSÃO}

Os resultados da pesquisa são apresentados da seguinte forma: caracterização da amostra, análises descritivas das variáveis e a influência do perfil dos respondentes nas variáveis.

\section{a. Caracterização da Amostra}

Evidenciou-se que, entre os respondentes, $63 \%$ fazem parte do gênero feminino e $37 \%$ são estudantes são do gênero masculino. Atualmente verifica-se o aumento significativo do nível de instrução da população geral e, principalmente, das mulheres que passam a apresentar mais de nove anos de estudo (FUNDAÇÃO CARLOS CHAGAS, 2015). Este aumento do percentual de mulheres que buscam aperfeiçoamento escolar proporcionou a elas maiores oportunidades de ingresso e estabilidade profissional, frente às atuais exigências quanto ao nível superior no mercado de trabalho. De acordo com o Cadastro Geral de Empregados e Desempregados (CAGED, 2015) e da Relação Anual de Informações Sociais do Ministério do Trabalho e Emprego (RAIS, 2015) a participação da mulher no mercado de trabalho tem sido crescente nos últimos anos.

Quanto à idade, a maior parcela dos estudantes possui 18 ou 19 anos $(32,6 \%)$, seguido de $27,6 \%$ que possuem 20 ou 21 anos. O estado civil informado pelos respondentes concentrou-se em grande maioria nos solteiros (92,9\%). Percebe-se, também, que $32,4 \%$ dos estudantes possuem renda familiar superior a $\mathrm{R} \$ 5.001,00$. Além disso, $63 \%$ são estudantes do curso de Administração e $37 \%$ cursam Ciências Contábeis, $75,1 \%$ são matriculados no curso pelo turno diurno e $24,9 \%$ no curso noturno, e a maioria dos respondentes está no início da graduação, entre o primeiro e o terceiro semestre.

A Tabela 1, a seguir, apresenta os dados gerais dos estudantes que responderam a pesquisa. 
Tabela 1 - Dados Gerais dos Respondentes

\begin{tabular}{|c|c|c|}
\hline Gênero & Renda Familiar & Semestre \\
\hline Feminino $(63 \%)$ & $\mathrm{R} \$ 401,00$ a $\mathrm{R} \$ 600,00$ (4\%) & $1^{\circ}$ Semestre $(\mathbf{1 8 , 4 \% )}$ \\
\hline Masculino (37\%) & $\mathrm{R} \$ 601,00$ a $\mathrm{R} \$ 900,00(4 \%)$ & $2^{\circ}$ Semestre $(25,7 \%)$ \\
\hline Idade & $\begin{array}{c}\mathrm{R} \$ 901,00 \text { a } \mathrm{R} \$ 1.500,00 \\
(\mathbf{1 3 , 6 \% )}\end{array}$ & $3^{\circ}$ Semestre $(16,8 \%)$ \\
\hline 16 ou 17 anos $(\mathbf{1 4 , 9 \% )}$ & $\begin{array}{c}\mathrm{R} \$ 1.501,00 \text { a } \mathrm{R} \$ 2.500,00 \\
(\mathbf{1 6 , 5 \% )}\end{array}$ & $4^{\circ}$ Semestre $(5,6 \%)$ \\
\hline 18 ou 19 anos $(32,6 \%)$ & $\begin{array}{c}\mathrm{R} \$ 2.501,00 \text { a } \mathrm{R} \$ 5.000,00 \\
(29,5 \%)\end{array}$ & 5o Semestre $(3,4 \%)$ \\
\hline 20 ou 21 anos $(27,6 \%)$ & Acima de $\mathrm{R} \$ 5.001,00(\mathbf{3 2 , 4 \% )}$ & 60 Semestre (14\%) \\
\hline 22 ou 23 anos $(12,7 \%)$ & Curso & $7^{\circ}$ Semestre $(5 \%)$ \\
\hline 24 anos ou mais $(12,2 \%)$ & Administração (63\%) & 80 Semestre $(8,9 \%)$ \\
\hline Estado Civil & Ciências Contábeis (37\%) & \multirow[t]{5}{*}{ 9o Semestre $(2,2 \%)$} \\
\hline Solteiro(a) $(\mathbf{9 2 , 9 \% )}$ & Turno & \\
\hline Casado(a) (5,5\%) & Diurno $(75,1 \%)$ & \\
\hline Divorciado(a) (0,5\%) & \multirow[t]{2}{*}{ Noturno $(\mathbf{2 4 , 9 \% )}$} & \\
\hline Outro $(1,1 \%)$ & & \\
\hline
\end{tabular}

Fonte: Os autores.

A partir da análise da Tabela 1, pode-se concluir a maioria dos estudantes participantes da pesquisa são do sexo feminino (63\%), possuem 18 ou 19 anos (32,6\%), solteiros (92,9\%), com renda superior a $\mathrm{R} \$ 5.001,00$, do curso de Administração (63\%), do período diurno $(75,1 \%)$, e entre o primeiro e o terceiro semestre $(60,9 \%)$.

\subsection{Análises Descritivas das Variáveis}

Primeiramente, analisam-se os resultados da pesquisa com base nas análises descritivas das variáveis e, após, a análise descritiva dos constructos. A seguir, na Tabela 2 , apresenta-se a média e o desvio padrão de cada variável para posterior análise.

Tabela 2 - Média e desvio padrão das variáveis

\begin{tabular}{l|c|c}
\hline Variáveis & Média & $\boldsymbol{\sigma}$ \\
\hline 1) Jogo todo tipo de lixo em qualquer lixeira & 3,022 & 1,2638 \\
\hline 2) Evito jogar papel no chão & 5,434 & 1,0790 \\
\hline 3) Falo sobre a importância do meio ambiente com as pessoas & 3,221 & 1,3274 \\
\hline $\begin{array}{l}\text { 4) Quando tenho vontade de comer alguma coisa e não sei o que é, } \\
\text { abro a geladeira e fico olhando o que tem dentro }\end{array}$ & 3,857 & 1,4722 \\
\hline 5) Evito desperdício dos recursos naturais & 3,779 & 1,1135 \\
\hline 6) Ajudo a manter as ruas limpas & 4,508 & 1,2764 \\
\hline
\end{tabular}

Estudos do CEPE [ISSN 1982-6729]. Santa Cruz do Sul, n. 44, p. 84-99, jul./dez. 2016. 


\begin{tabular}{|c|c|c|}
\hline 7) Evito comprar produtos que são feitos de plástico & 2,000 & 0,9103 \\
\hline 8) Enquanto escovo os dentes deixo a torneira aberta & 1,692 & 1,2186 \\
\hline 9) Separo o lixo conforme o tipo & 3,144 & 1,5359 \\
\hline $\begin{array}{l}\text { 10) Guardo o papel que não quero mais na bolsa, quando não } \\
\text { encontro uma lixeira por perto }\end{array}$ & 5,239 & 1,2069 \\
\hline 11) Entrego papéis para reciclagem & 2,503 & 1,3889 \\
\hline 12) Quando estou tomando banho, fecho a torneira para me ensaboar & 2,071 & 1,4376 \\
\hline 13) Economizo água quando possível & 4,243 & 1,2765 \\
\hline 14) Quando vejo alguém jogando papel na rua, pego e jogo na lixeira & 2,593 & 1,2700 \\
\hline 15) Colaboro com a preservação da cidade onde vivo & 3,961 & 1,2692 \\
\hline 16) Quando não encontro lixeira por perto, jogo latas vazias no chão & 1,408 & 0,8320 \\
\hline $\begin{array}{l}\text { 17) Evito usar produtos fabricados por uma empresa quando sei que } \\
\text { essa empresa está poluindo o meio ambiente }\end{array}$ & 2,249 & 1,2949 \\
\hline 18) Apago a luz quando saio de ambientes vazios & 4,851 & 1,3723 \\
\hline 19) Evito desperdício de energia & 4,527 & 1,2688 \\
\hline 20) Evito comer alimentos transgênicos & 2,242 & 1,1971 \\
\hline $\begin{array}{l}\text { 21) Mobilizo as pessoas nos cuidados necessários para a } \\
\text { conservação dos espaços públicos }\end{array}$ & 2,835 & 1,3807 \\
\hline $\begin{array}{l}\text { 22) Compro comida sem me preocupar se têm conservantes ou } \\
\text { agrotóxicos }\end{array}$ & 3,973 & 1,5249 \\
\hline 23) Deixo a televisão ligada mesmo sem ninguém assistindo & 2,530 & 1,481 \\
\hline 24) Entrego as pilhas usadas nos postos de coleta & 2,367 & 1,5241 \\
\hline 25) Participo de atividades que cuidam do meio ambiente & 2,171 & 1,1778 \\
\hline $\begin{array}{l}\text { 26) Evito ligar vários aparelhos elétricos ao mesmo tempo nos } \\
\text { horários de maior consumo de energia }\end{array}$ & 2,434 & 1,3999 \\
\hline
\end{tabular}

Fonte: Os autores.

Como se pode perceber na Tabela 2, as médias estão situadas entre os valores de 1,408 (menor média) e 5,434 (maior média). Observa-se, ainda, que as variáveis com médias mais altas, em geral, apresentam um desvio padrão baixo, o que representa de certo modo conformidade de opiniões para estas variáveis.

A variável que apresentou a maior média foi a Q2 - Evito jogar papel no chão, com média de 5,434 , o que indica que os estudantes que participaram da pesquisa se mostram preocupados com o despejo de resíduos no ambiente, possibilitando assim a colaboração para um meio ambiente limpo. A variável Q2 - Guardo o papel que não quero mais na bolsa, quando não encontro uma lixeira por perto, também apresentou uma elevada média $(5,239)$, corroborando com a variável mais elevada. Sendo assim, esses resultados são positivos, visto que, de acordo com Gonçalves, Tanaka e Amedomar (2013), a destinação correta de resíduos sólidos é um dos maiores desafios a ser 
enfrentado pela sociedade moderna, em decorrência da elevada quantidade de resíduos gerados pela população diariamente.

Outras duas variáveis que também apresentaram um alto índice de respostas foi Q18 - Apago a luz quando saio de ambientes vazios, com média de 4,851, e Q19 - Evito desperdício de energia, com média de 4,527. Essas variáveis representam a preocupação dos respondentes com a questão do uso da energia, os mesmos demonstram estar conscientes em relação ao uso correto da energia, evitando assim os desperdícios e maiores gastos financeiros para os mesmos.

A primeira revela que os respondentes têm clareza em relação a consciência energética, procurando desligar as luzes de ambientes que não estão sendo utilizados. A segunda, também relacionada a questão energética, corresponde a economia de energia, que talvez pode-se ser justificado pelo crescente custo da energia, e das políticas de incentivo a economia da mesmo. Conforme Ting (2012), o cenário atual é preocupante, principalmente porque a quantidade de recursos energéticos extraído está sendo maior do que o encontrado, o que também está relacionado a superpopulação e o crescimento da demanda de energia a nível mundial. O problema da energia está pautado na degradação do meio ambiente e consequentemente na questão econômica, pois o preço de comercialização de energia é considerado muito alto. Desse modo, os respondentes parecem estar engajados nessas práticas, o que pode ser considerado um resultado positivo na busca pela eficiência energética.

No entanto, algumas variáveis apresentaram médias mais baixas em comparação com as demais. A variável Q16 - Quando não encontro lixeira por perto, jogo latas vazias no chão, obteve a menor média $(1,408)$, indicando que apesar de estarem conscientes em relação a conservação do meio ambiente, do destino adequado para os dejetos, quando não há um local para depósitos, os mesmos não se importam em jogá-los no meio ambiente. A variável Q8 - Enquanto escovo os dentes deixo a torneira aberta foi a segunda média mais baixa e apresentou uma média de $(1,692)$. Isto demonstra que os respondentes não costumam economizar água durante uma prática diária, deixando a torneira aberta na higiene bucal. Para Oliveira et al. (2013), as iniciativas de racionalização do uso e de reuso de água se constituem em elementos fundamentais em qualquer iniciativa de conservação, pois atua de forma direta na disponibilidade deste recurso natural para atender o crescimento da população, para implantação de novas indústrias e na preservação e conservação do meio ambiente.

Com o crescimento da população urbana, e o desenvolvimento desta a tendência é que o consumo de água tratada aumente e com ele o índice de desperdício. De acordo com o Instituto Akatu (2015), deixar a torneira aberta durante a higiene bucal pode gastar desperdiçar de 12 a 20 litros de água por minuto. Assim, a simples prática de fechar a torneira contribuiria muito para a economia e a sustentação desse recurso hídrico.

\subsection{Influência do Perfil dos Respondentes nas Variáveis}

Os procedimentos estatísticos adotados nesta etapa foram calcular a média e o desvio padrão das variáveis e, após, realizar testes estatísticos de diferença de médias (teste $T$ e teste 
ANOVA) para verificar se as diferenças foram significativamente representativas, ou seja, com significância inferior à 0,05 .

A seguir, a Tabela 3 apresenta a influência do gênero nas variáveis que apresentaram diferenças significativamente representativas nas médias a partir da realização do Teste $T$.

Tabela 3 - Influência do gênero nas variáveis

\begin{tabular}{|c|c|c|c|c|}
\hline Variável & Gênero & Média & $\bar{\sigma}$ & Sig. \\
\hline \multirow{2}{*}{ 2) Evito jogar papel no chão } & Feminino & 5,605 & 0,9832 & \multirow{2}{*}{0,007} \\
\hline & Masculino & 5,134 & 1,1793 & \\
\hline \multirow{2}{*}{ 6) Ajudo a manter as ruas limpas } & Feminino & 4,708 & 1,2584 & \multirow{2}{*}{0,004} \\
\hline & Masculino & 4,149 & 1,234 & \\
\hline \multirow{2}{*}{$\begin{array}{l}\text { 10) Guardo o papel que não quero mais na bolsa, } \\
\text { quando não encontro uma lixeira por perto }\end{array}$} & Masculino & 5,637 & 0,7567 & \multirow{2}{*}{0,000} \\
\hline & Feminino & 4,545 & 1,5006 & \\
\hline \multirow{2}{*}{$\begin{array}{l}\text { 16) Quando não encontro lixeira por perto, jogo } \\
\text { latas vazias no chão }\end{array}$} & Feminino & 1,283 & 0,7731 & \multirow{2}{*}{0,010} \\
\hline & Masculino & 1,631 & 0,8939 & \\
\hline \multirow{2}{*}{ 18) Apago a luz quando saio de ambientes vazios } & Feminino & 5,150 & 1,1435 & \multirow{2}{*}{0,001} \\
\hline & Feminino & 4,358 & 1,5831 & \\
\hline \multirow{2}{*}{ 19) Evito desperdício de energia } & Masculino & 4,711 & 1,15 & \multirow[b]{2}{*}{0,022} \\
\hline & Feminino & 4,239 & 1,4044 & \\
\hline
\end{tabular}

Fonte: Os autores.

A partir da análise da Tabela 3, percebe-se uma maior conscientização ecológica por parte das mulheres, uma vez que para todas as variáveis que apresentaram diferenças significativas nas médias (Q2 - Evito jogar lixo no chão; Q6 - Ajudo a manter as ruas limpas; Q10 - Guardo o papel que não quero mais na bolsa, quando não encontro uma lixeira por perto; Q16 - Quando não encontro lixeira por perto, jogo latas vazias no chão; Q18 - Apago a luz quando saio de ambientes vazios; e Q19 - Evito desperdício de energia), as participantes do gênero feminino apresentaram médias mais acordadas com os preceitos de um comportamento ecológico em comparação com os respondentes do gênero masculino.

$\mathrm{Na}$ Tabela 4, a seguir, apresentam-se as variáveis com diferenças significativamente representativas nas médias quando avaliadas sob a influência da idade a partir de um teste ANOVA. 
Tabela 4 - Influência da idade nas variáveis

\begin{tabular}{|c|c|c|c|c|}
\hline Variável & Idade & Média & $\bar{\sigma}$ & Sig. \\
\hline \multirow{5}{*}{$\begin{array}{l}\text { 15) Colaboro com a preservação da cidade onde } \\
\text { vivo }\end{array}$} & 16 ou 17 anos & 4,577 & 1,2385 & \multirow{5}{*}{0,038} \\
\hline & 18 ou 19 anos & 3,655 & 1,3052 & \\
\hline & 20 ou 21 anos & 3,940 & 1,1323 & \\
\hline & 22 ou 23 anos & 4,000 & 1,3093 & \\
\hline & $\begin{array}{l}24 \text { anos ou } \\
\text { mais }\end{array}$ & 4,136 & 1,2458 & \\
\hline \multirow{5}{*}{$\begin{array}{l}\text { 26) Evito ligar vários aparelhos elétricos ao mesmo } \\
\text { tempo nos horários de maior consumo de energia }\end{array}$} & 16 ou 17 anos & 2,667 & 1,4936 & \multirow{5}{*}{0,049} \\
\hline & 18 ou 19 anos & 2,169 & 1,2886 & \\
\hline & 20 ou 21 anos & 2,240 & 1,2216 & \\
\hline & 22 ou 23 anos & 2,696 & 1,6358 & \\
\hline & $\begin{array}{l}24 \text { anos ou } \\
\text { mais }\end{array}$ & 3,091 & 1,5090 & \\
\hline
\end{tabular}

Fonte: Os autores.

A partir da análise da Tabela 4, percebe-se que os jovens com idade de 16 e 17 anos são os que mais tem o sentimento de que estão colaborando coma preservação da cidade onde vivem (4,577). Em compensação, na análise desta mesma variável, nota-se que os jovens de 18 e 19 apresentaram a menor média nesta questão $(3,655)$. Quando analisada a variável Q26 - Evito ligar vários aparelhos elétricos ao mesmo tempo nos horários de maior consumo de energia, observa-se que, apesar da média não ser muito alta nenhuma das faixas etárias, em geral os respondentes mais velhos (principalmente aqueles com idade superior a 24 anos) têm maior consciência em evitar 0 consumo exagerado de energia em determinados horários.

A seguir, na Tabela 5, apresenta-se a influência da renda familiar nas variáveis que obtiveram diferenças significativamente representativas nas médias, a partir do Teste ANOVA.

Tabela 5 - Influência da renda familiar nas variáveis

\begin{tabular}{|c|c|c|c|c|}
\hline Variável & Renda Familiar & Média & $\sigma$ & Sig. \\
\hline \multirow{6}{*}{ 5) Evito desperdício dos recursos naturais } & $\mathrm{R} \$ 401,00$ a $\mathrm{R} \$ 600,00$ & 3,286 & 0,9512 & \multirow{6}{*}{0,016} \\
\hline & $\mathrm{R} \$ 601,00$ a $\mathrm{R} \$ 900,00$ & 4,429 & 0,7868 & \\
\hline & $\begin{array}{c}\mathrm{R} \$ 901,00 \text { a } \mathrm{R} \$ \\
1.500,00\end{array}$ & 4,087 & 0,996 & \\
\hline & $\begin{array}{c}\mathrm{R} \$ 1.501,00 \text { a } \mathrm{R} \$ \\
2.500,00\end{array}$ & 3,690 & 1,0387 & \\
\hline & $\begin{array}{c}\mathrm{R} \$ 2.501,00 \text { a } \mathrm{R} \$ \\
5.000,00\end{array}$ & 4,058 & 1,1274 & \\
\hline & Acima de $R \$ 5.001,00$ & 3,456 & 1,1506 & \\
\hline \multirow{6}{*}{ 13) Economizo água quando possível } & $\mathrm{R} \$ 401,00$ a $\mathrm{R} \$ 600,00$ & 3,286 & 0,7559 & \multirow{6}{*}{0,019} \\
\hline & $\mathrm{R} \$ 601,00$ a $\mathrm{R} \$ 900,00$ & 3,429 & 0,9759 & \\
\hline & $\begin{array}{c}\mathrm{R} \$ 901,00 \text { a } \mathrm{R} \$ \\
1.500,00\end{array}$ & 4,500 & 1,3188 & \\
\hline & $\begin{array}{c}\mathrm{R} \$ 1.501,00 \text { a } \mathrm{R} \$ \\
2.500,00\end{array}$ & 4,621 & 1,1776 & \\
\hline & $\begin{array}{c}\mathrm{R} \$ 2.501,00 \text { a } \mathrm{R} \$ \\
5.000,00\end{array}$ & 4,442 & 1,3197 & \\
\hline & Acima de $\mathrm{R} \$ 5.001,00$ & 4,000 & 1,2933 & \\
\hline
\end{tabular}




\begin{tabular}{|c|c|c|c|c|}
\hline \multirow{6}{*}{ 20) Evito comer alimentos transgênicos } & $\mathrm{R} \$ 401,00$ a $\mathrm{R} \$ 600,00$ & 1,571 & 0,7868 & \multirow{6}{*}{0,050} \\
\hline & $\mathrm{R} \$ 601,00$ a $\mathrm{R} \$ 900,00$ & 3,143 & 1,7728 & \\
\hline & $\begin{array}{c}\mathrm{R} \$ 901,00 \text { a } \mathrm{R} \$ \\
1.500,00\end{array}$ & 2,417 & 1,1765 & \\
\hline & $\begin{array}{c}\mathrm{R} \$ 1.501,00 \text { a } \mathrm{R} \$ \\
2.500,00\end{array}$ & 2,517 & 1,2989 & \\
\hline & $\begin{array}{c}\mathrm{R} \$ 2.501,00 \text { a } \mathrm{R} \$ \\
5.000,00\end{array}$ & 2,288 & 1,1772 & \\
\hline & Acima de $R \$ 5.001,00$ & 1,982 & 1,0605 & \\
\hline
\end{tabular}

Fonte: Os autores.

Nota-se, a partir da análise da Tabela 5 , que os respondentes com renda familiar entre $R \$$ 601,00 e $R \$ 900,00$ são os que mais evitam desperdiçar os recursos naturais $(4,429)$ e, também, os que menos predispostos a consumir produtos de origem transgênica $(3,143)$. Destaca-se, ainda, que a economia de água é realizada de forma mais ativa pelos respondentes com renda familiar entre $\mathrm{R} \$$ $1.501,00$ a $R \$ 2.500,00$. Estes dados revelam, para estes participantes da pesquisa, que um nível econômico mais ou menos favorecido não significa maior preocupação com questões como desperdício de recursos naturais, economia de água e consumo de alimentos orgânicos.

A Tabela 6, a seguir, apresenta as variáveis que obtiveram diferenças significativamente representativas quando analisadas sob a influência do curso a partir do Teste $\mathrm{T}$.

Tabela 6 - Influência do curso nas variáveis

\begin{tabular}{|c|c|c|c|c|}
\hline Variável & Curso & Média & $\sigma$ & Sig. \\
\hline \multirow[b]{2}{*}{ 1) Jogo todo tipo de lixo em qualquer lixeira } & Administração & 2,843 & 1,1694 & \multirow[b]{2}{*}{0,033} \\
\hline & $\begin{array}{l}\text { Ciências } \\
\text { Contábeis }\end{array}$ & 3,270 & 1,3820 & \\
\hline \multirow{2}{*}{$\begin{array}{l}\text { 7) Evito comprar produtos que são feitos de } \\
\text { plástico }\end{array}$} & Administração & 2,083 & 0,9342 & \multirow[b]{2}{*}{0,030} \\
\hline & $\begin{array}{l}\text { Ciências } \\
\text { Contábeis }\end{array}$ & 1,781 & 0,7657 & \\
\hline \multirow{2}{*}{$\begin{array}{l}\text { 8) Enquanto escovo os dentes deixo a torneira } \\
\text { aberta }\end{array}$} & Administração & 1,862 & 1,3975 & \multirow[b]{2}{*}{0,002} \\
\hline & $\begin{array}{l}\text { Ciências } \\
\text { Contábeis }\end{array}$ & 1,359 & 0,7208 & \\
\hline \multirow{2}{*}{$\begin{array}{l}\text { 12) Quando estou tomando banho, fecho a } \\
\text { torneira para me ensaboar }\end{array}$} & Administração & 2,220 & 1,5891 & \multirow[b]{2}{*}{0,030} \\
\hline & $\begin{array}{l}\text { Ciências } \\
\text { Contábeis }\end{array}$ & 1,766 & 1,1232 & \\
\hline \multirow{2}{*}{$\begin{array}{l}\text { 21) Mobilizo as pessoas nos cuidados } \\
\text { necessários para a conservação dos espaços } \\
\text { públicos }\end{array}$} & Administração & 3,009 & 1,4109 & \multirow[b]{2}{*}{0,019} \\
\hline & $\begin{array}{l}\text { Ciências } \\
\text { Contábeis }\end{array}$ & 2,500 & 1,2724 & \\
\hline
\end{tabular}

Fonte: Os autores.

A partir da análise da Tabela 6, percebe-se que os estudantes de Ciências Contábeis têm mais consciência do que os acadêmicos de Administração quando questionados sobre o desperdício de água durante a higiene bucal, uma vez que na questão Q8 - Enquanto escovo os dentes deixo a torneira aberta apresentaram maior média $(1,862)$. Em contrapartida, os estudantes de Administração têm mais cuidado na separação do lixo, evitam o consumo de produtos feitos de plástico, tem mais atenção para evitar o desperdício de água durante o banho, e tem mais preocupação com a 
preservação dos espaços públicos, quando comparados com os acadêmicos do curso de Ciências Contábeis.

\section{CONSIDERAÇÕES FINAIS}

O presente trabalho teve como objetivo analisar o comportamento ecológico dos estudantes dos cursos de Administração e de Ciência Contábeis da Universidade Federal de Santa Maria.

A partir da análise dos resultados, pode-se caracterizar a amostra como sendo a maioria dos respondentes do gênero feminino, com 18 ou 19 anos, solteiros, com renda superior a $R \$ 5.001,00$, do curso de Administração, do período diurno, e entre o primeiro e o terceiro semestre.

Percebeu-se que os estudantes participantes da pesquisa têm um comportamento ecológico esperado principalmente em questões como o resguardo em jogar papel no chão, aguardando encontrar uma lixeira para poder dar a correta destinação. Também, demonstraram ter a preocupação com o consumo desnecessário de energia elétrica, apagando as lâmpadas ao deixar um ambiente. No entanto, algumas questões como o desperdício de água ao escovar os dentes ainda parecem ser bastante comuns entre esses jovens, não tendo completo entendimento do quão importante é o consumo consciente nas atividades diárias deste recurso tão essencial para a nossa sobrevivência.

Ao analisarmos a influências de algumas questões de perfil sobre as variáveis, percebeu-se que as mulheres respondentes, quando comparadas aos homens, tem maior consciência em não jogar lixo no chão, ajudam a manter as ruas limpas, guardam o papel até encontram uma lixeira, evitam jogar latas vazias no chão, apagam a luz ao sair dos ambientes vazios e evitam o desperdício de energia.

Ainda, evidenciou-se que os acadêmicos mais jovens que participaram da pesquisa têm são os que mais sentem que estão colaborando com a preservação da cidade que vivem, e, em contrapartida, os respondentes de faixa etária mais elevada, têm maior preocupação em evitar o uso de aparelhos elétricos em horários de maior consumo de energia. Ainda, quando se analisou as variáveis sob a influência da renda familiar, notou-se que o nível econômico dos acadêmicos não foi fator determinante para uma maior ou menor escala de comportamento ecológico.

Em uma última análise, verificou-se que os estudantes de Administração têm maior consciência do que os acadêmicos de Ciências Contábeis em questões como a separação correta do lixo, o resguardo no consumo de produtos feitos de plásticos, cuidado no desperdício de água durante o banho e maior cuidado com a preservação de espaços públicos.

As limitações deste estudo estão na escolha da amostra, pois a mesma se caracteriza como não-probabilística por acessibilidade, o que impossibilita a inferência destes resultados a todos os discentes dos cursos de Administração e Ciências Contábeis da UFSM. Além disso destaca-se que estes resultados não podem ser generalizados para outros contextos. Assim, sugere-se para trabalhos futuros a aplicação desta metodologia para conhecer o comportamento ecológico de 
acadêmicos de outros cursos da instituição e, até mesmo, de acadêmicos de outras instituições públicas e privadas a fim de gerar um comparativo entre estes públicos.

Estudos do CEPE [ISSN 1982-6729]. Santa Cruz do Sul, n. 44, p. 84-99, jul./dez. 2016. https://online.unisc.br/seer/index.php/cepe/index 


\section{REFERÊNCIAS}

ALMEIDA, F. O bom negócio da sustentabilidade. Rio de Janeiro: Nova Fronteira, 2002.

AXELROD, L. J.; LEHMAN, D.R. Responding to environmental concerns: what factors guide individual action? Journal Environmental Psycholgy, n. 13, p. 149-159, 1993.

BEURON, T. A. Valores organizacionais e pessoais e comportamentos ecológicos: uma investigação no contexto da gestão socioambiental. Dissertação de Mestrado, UFSM, 2012.

BRITO, E. Z.; LOMBARDI, M. S. Desenvolvimento sustentável como fator de competitividade. In: ENANPAD, 31, 2007, Rio de Janeiro. Anais. Rio de Janeiro: ANPAD, 2007.

CADASTRO GERAL DE EMPREGADOS E DESEMPREGADOS - CAGED. Disponível em: http://www.mte.gov.br/imprensa/cresce-a-participacao-da-mulher-no-mercado-de-trabalho.htm. Acesso em: 16 outubro 2015.

CAMPOS, C. B.; POL, E. As crenças ambientais de trabalhadores provenientes de empresa certificada por SGA podem predizer comportamentos pró-ambientais fora da empresa? Estudos de Psicologia, 15 (2), Mai-Ago, 2010, 199-206.

DIAS, S. L. F. G; et al... Comportamento ecológico: uma tipologia para repensar a formação de gestores na graduação. Anais... XXVI ENEGEP - Fortaleza, CE, Brasil, 9 a 11 de Outubro de 2006.

DUNLAP, R. E.; VAN LIERE, K. D. The "new environmental paradigm": a proposed measuring instrument and preliminary results. Journal of Environmental Education, n. 9, pp. 10-19, 1978.

ELKINGTON, J. Canibais com garfo e faca. São Paulo: Makron Books, 2001.

FRANCO, I. K.; Valores e comportamento ecológico: uma análise comparative e evolutiva dos alunos de dois cursos de graduação da USP.Dissertação de Mestrado, USP, 2012.

FREITAS, J. Sustentabilidade: Direito ao Futuro. 2. ed. Minas Gerais: Fórum, 2012.

FUNDAÇÃO CARLOS CHAGAS. Mulheres brasileiras, educação e trabalho. Disponível em: http://www.fcc.org.br/mulher/series_historicas/mbet.html. Acesso em: 16 outubro 2015.

GONÇALVES, M. A.; TANAKA, A. K.; AMEDOMAR, A. A. A destinação final dos resíduos sólidos urbanos: alternativas para a cidade de São Paulo através de casos de sucesso. Future Studies Research Journal, v. 5, n. 1, p. 96-129, jan./jun. 2013.

INSTITUTO AKATU. Água: Manual de Sobrevivência para a Crise. 2015. Disponível em www.akatu.org.br. Acesso em 10 de outubro de 2015.

JACOBI, P. Educação ambiental, cidadania e sustentabilidade. Cadernos de Pesquisa, n. 118, p. 189205, 2003.

KAISER, F. G.; FUHLER, U. Ecological behaviour's dependency on different forms of knowledge. Appl Psychol Int Rev, n. 52, pp. 598-613, 2003.

KARP, D. G. Values and their effect on pro-environmental behavior. Environment and Behavior 28(1), 111-133, 1996.

MALHOTRA, N. Pesquisa de marketing: uma orientação aplicada. 4. ed. Porto Alegre: Bookman, 2006.

OLIVEIRA, N. M. de; et al.. Reuso da água: um novo paradigma de sustentabilidade. Élisée, a Porangatu, v.2, n.1, p.146-157, jan./jul. 2013.

PATO, C. M. L. Comportamento ecológico: relações com valores pessoais e crenças ambientais. (Tese de doutorado não publicada). Universidade de Brasília, Brasília, 2004. 
PATO, C.; TAMAYO, A. A escala de comportamento ecológico: desenvolvimento e validação de um instrumento de medida. Estudos de Psicologia, n. 11, pp. 289-296, 2006.

RELAÇÃO ANUAL DE INFORMAÇÕES SOCIAIS DO MINISTÉRIO DO TRABALHO E EMPREGO RAIS. Disponível em: http://www.mte.gov.br/imprensa-mercado-de-trabalho-rais-crescimentomulheres.htm. Acesso em: 16 outubro 2015.

RICKLEFS, R. A economia da natureza. 5. ed. Rio de Janeiro: Guanabara Koogan S.A., 2003.

ROCHA, A. C.da. et.al. Um panorama sobre os estudos relacionados à temática educação e sustentabilidade. Revista GUAL, Florianópolis, v. 6, n. 2, p. 160-184, abr. 2013.

SILVA, M. E. et al .Um espelho, um reflexo! A Educação para a sustentabilidade como subsídio para uma tomada de decisão consciente do administrador. Rev. Adm. Mackenzie, v. 14, n. 3, p. 154-182, MAIO/JUN 2013.

TING, L. S.; BIN MOHAMMED, A. H.; CHOONG, W. W. Proposed implementation strategies for energy sustainability on a Malaysian university campus. Business Strategy Series, 13(5), 208-213, 2012.

TRIVIÑOS, A. N. S. Introdução à pesquisa em Ciências Sociais: a pesquisa qualitativa em educação. São Paulo: Atlas, 1987.

ZELEZNY, L. C.; SCHULTZ, P. W. Promoting environmentalism. Journal of Social Issues, v. 56, n. 3 , pp. 365-371, 2000. 